\title{
Topical Fluorouracil Regimen
}

National Cancer Institute

\section{Source}

National Cancer Institute. Topical Fluorouracil Regimen. NCI Thesaurus. Code C160127.

A chemotherapy regimen consisting of topical fluorouracil that may be used in the treatment of penile cancer. 